\title{
Student-Generated Problems that Reverse Engineer YouTube Videos
}

\section{Prof. Matthew W. Liberatore, University of Toledo}

Matthew W. Liberatore is a Professor of Chemical Engineering at the University of Toledo. He earned a B.S. degree from the University of Illinois at Chicago and M.S. and Ph.D. degrees from the University of Illinois at Urbana-Champaign, all in chemical engineering. His current research involves the rheology of complex fluids as well as active learning, reverse engineering online videos, and interactive textbooks.

\section{Uchenna Asogwa}

\section{Dr. Amanda Portis Malefyt, Trine University}

Amanda Malefyt is currently Chair and Associate Professor in the McKetta Department of Chemical and Bioprocess Engineering at Trine University. She received her Ph.D from Michigan State University and bachelor's degree from Trine (formerly Tri-State) University. Her research interests include engineering education and nucleic acid therapeutics.

\section{Dr. Charlene M. Czerniak, University of Toledo}

Charlene M. Czerniak is a professor at The University of Toledo in the department of Curriculum and Instruction. She received her Ph.D. in science education from The Ohio State University. A former elementary teacher in Bowling Green, $\mathrm{OH}$, she teaches classes in grant writing, elementary science education, and science teacher leadership. Professor Czerniak has authored and co-authored over 50 articles. Her publications have appeared in the Journal of Science Teacher Education, Journal of Research in Science Teaching, School Science and Mathematics, Science Scope, and Science and Children. Professor Czerniak is co-author of a textbook published by Routledge on project based science teaching. She also has five chapters in books and illustrated 12 children's science education books. Most recently, Czerniak authored a chapter entitled Interdisciplinary Science Teaching in the Handbook of Research on Science Education, published by Lawrence Erlbaum and Associates. Professor Czerniak has been an author and director of numerous grant funded projects in excess of $\$ 30$ million dollars that targeted professional development of science teachers. She has made frequent presentations at national and regional conferences that focus on her research interests on teachers' beliefs about teaching science, professional development for elementary and middle grades teachers, science education reform, and school improvement. She is an active member in the Association for Science Teacher Education (ASTE), the National Association of Research in Science Teaching (NARST), the School Science and Mathematics Association (SSMA), and the National Science Teachers Association (NSTA) and reviews manuscripts for the journals associated with these organizations. For five years, she served as editor of the Journal of Science Teacher Education, the professional journal of the Association for Science Teacher Education. She has served on numerous committees for AETS, NARST, SSMA, and NSTA. Charlene Czerniak was the President of the School Science and Mathematics Association for two years, and she served as the President of the National Association for Research in Science Teaching (NARST) from 2008-2009. She received the 2008 Distinguished Alumni Award for Service from The University of Toledo Judith Herb College of Education and the 2008 Research Award from the Judith Herb College of Education. In 2010, she received the George Mallinson Distinguished Service Award from the School Science and Mathematics Association (SSMA), which is the highest award given by SSMA. In 2012, she was named Distinguished University Professor at The University of Toledo, which the highest award bestowed on faculty.

\section{Dr. Gale A. Mentzer, Acumen Research and Evaluation, LLC}

Gale A. Mentzer, PhD, the owner and director of Acumen Research and Evaluation, LLC, has been a professional program evaluator since 1998. She holds a PhD in Educational Research and Measurement from The University of Toledo and a Master of Arts in English Literature and Language-a unique combination of specializations that melds quantitative and qualitative methodologies. She and has extensive experience in the evaluation of projects focused on STEM education including evaluations of several multi-million dollar federally funded projects. Previously she taught graduate level courses for the College of Education at The University of Toledo in Statistics, Testing and Grading, Research Design, and Program Evaluation. 


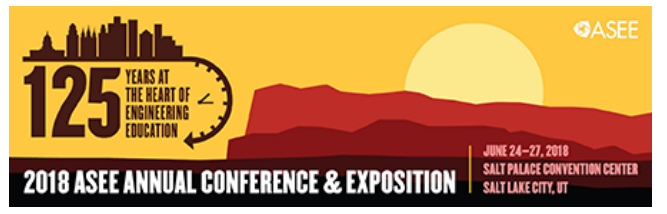

Paper ID \#23170

T. Ryan Duckett, Acumen Research and Evaluation 


\title{
Developing problem solving skills using student-generated problems that reverse engineer YouTube videos
}

\begin{abstract}
Homework problems from many textbooks have solutions manuals on the Internet. Students find solutions manuals and focus on getting the right answer put little or no effort on learning. Problem solving is a signature skill of engineers that is in high demand across industries. Here, problem solving is employed when students apply course concepts to reverse engineer YouTube videos and create new homework-quality problem statements and solutions. This research seeks to examine the rigor of YouTube problems and the effect of YouTube problems on the problem-solving skills of students. A quasi-experimental, treatment/control group design is employed and data is collected and evaluated using a variety of tools. The rigor of YouTube problems is examined using the NASA Task Load Index (TLX). Problem solving skill are examined using Problem definition, representing the problem, organizing information, calculations, evaluating the solution, solution communication, and self-assessment (PROCESS) and other tools.
\end{abstract}

\section{Introduction}

$21^{\text {st }}$ century undergraduate students are digital natives. Almost all of these students have had access to computers and the Internet from a young age. Technology-savvy students enjoy advantages, such as accessibility to course related information from the Internet enabling them to look up unit conversions, find physical properties, or verify an equation effortlessly. However, faculty members are faced with challenges associated with negative technology-driven behaviors in higher education. For example, handheld technologies allowing students to send text messages or tweets contributing to shorter student attention spans [1]. Also, easy accessibility of textbook solution manuals online intended for instructors makes it easier for students to cheat and copy textbook homework solutions instead of solving them [2].

Granted that many textbook solutions manuals are available on the web, a good number of students perceive copying solution manuals as equivalence to learning the material [3]. In contrast to this perception, both homework and exam scores have shown, in the case of one semester of material and energy balance students, that copying the solutions manual as a form of studying does not lead to success in the course [4]. Therefore, finding new ways to develop interesting and textbookquality homework problems to both engage and educate digital native students is the topic of this paper.

Aside from educational integrity, engaging digital natives could lead to an improvement in their problem-solving skills. Moreover, Accrediting Board for Engineering and Technology (ABET) standards stress the need for engineering graduates to have the ability to solve problems in addition to being knowledgeable of current issues. In addition, complex problem solving skills is predicted to be the most prevalent skill to thrive in the workforce in 2020 [5]. Real world problems help students' understanding to become more integrated [6, 7]. However, most instructional approaches limit students' ability to transfer learning by focusing on course-specific information. 
Active learning involves students' participation. Active learning and student-centered pedagogies leads to better learning compared to traditional teacher-centric techniques, such as lecture [8-12]. For an activity to truly qualify as active learning, students' enthusiasm is advantageous. Pedagogies should adapt to current students' strengths by integrating their digital habits into the higher-education classroom [9, 13-17]. In fact, technology in the classroom is expected by many digital natives (e.g., clickers, tablets, just-in-time teaching, YouTube) [18-22]. Implementation of technology as a form of active learning is a useful tool because it connects students and learning $[23,24]$. Therefore, engaging the current generation of students using technology, like YouTube, in a positive way is one motivation directing this project.

Characteristics of problems such as complexity of problems influence problem solving performance $[25,26]$. However, visual representation is an important part of successfully solving complex problems [25, 27-31]. The role of visuals in enhancing learning has been studied and shown to trump the other senses in creating short and long-term memory [27, 32]. Visual learning methods open new ways of problem solving, thinking, as well as enhance the education and practice of science and engineering [28, 29, 33]. In addition, the seemingly endless information and content on the Internet, and specifically YouTube videos, provide an array of contexts to connect engineering fundamentals to visual situations, which can be motivating and interesting. Therefore, the engagement and productive learning from searching for, identifying, watching, and translating YouTube videos ties in well with cutting-edge research in neuroscience and learning science.

In addition, preparing students so that they can solve problems in a variety of settings as well as apply classroom engineering concepts in real world situation is a major role of engineering education. This research is based on the grounds that problem solving skill is promoted through YouTube pedagogy since it integrates variety of real world problems. This feature motivates students to spend the time needed to solve complex problems since they find them interesting. While the study is underway, some of the content of this paper has been previously published.

\section{Materials: Creating YouTube Problems}

YouTube pedagogy started as a way to encourage attendance, introduce and engage students during the Fall 2008 semester where first five minutes of class was dedicated to course related videos selected by groups of 3 or 4 students. After the implementation, the students gave YouTube Fridays favorable re-marks. The goal was to introduce the students to chemical engineering and what chemical engineers do, which was very successful based on the written reports and the data collected from the evaluations [18].

Following the success based on surveys related to engagement, the following year, students were required to select video from YouTube and create engineering estimate problems related to the topic of the course (either thermodynamics or material and energy balances). Students' feedback on their comfort with open-ended problems was solicited. While a majority felt they had a better understanding of the course topic of thermodynamics (63\% strongly agree/agree), a larger majority could relate thermodynamics to real world phenomena and felt confident solving engineering estimate problems (79\% and 69\% strongly agree/agree, respectively). In addition, over $40 \%$ of the 
class thought YouTube Fridays helped them learn the course material. Recurring response from the free response questions stated that real situations are much harder than class problems since there are so many unknowns. The vast majority of the feedback on YouTube Fridays was positive and will help to improve the students' ability to apply classroom concepts to open-ended, real world situations [21].

Another study successfully established the efficacy of student-written YouTube problems. The quality of one set of student-written problems was compared with textbook homework problems by using two class sections of a junior level heat transfer course. The course comprises of two major topics; parallel and series resistances and the transient heat transfer. Both sections of the course were assigned weekly homework, taken out of the textbook for the parallel and series topic. While for the transient heat transfer, the students in the control section completed textbook homework and those in the YouTube section completed YouTube homework assignment written by students in a senior-level transport phenomena course in the previous semester. The exam question covered both topics; first, problem for parallel and series was lifted from textbook while the second problem which covered transient heat transfer was a student-written problem from YouTube. Student achievement on exam problems in a heat transfer course compared the students in the section completing only textbook homework problems to students completing studentwritten YouTube homework problems. For the first problem, students in both sections demonstrated no statistical difference while students in the YouTube section scored higher on the second problem. This outcome of this study provides motivation for a larger, more rigorous study to quantify problem solving skills exhibited from solving YouTube problems [20].

\section{Example YouTube Problems}

Variety of problems that can be implemented in class, as part of homework sets, or in quizzes/exams has been developed with the YouTube pedagogy. Four problem types which examine the student's learning at the numerous levels of Bloom's taxonomy [34], and Examples are detailed in the publications [18, 20,21].

Table 1. Problem types, taxonomy verbs, and examples generated using YouTube videos

\begin{tabular}{|l|l|l|}
\hline Problem Type & Bloom's verbs & Example \\
\hline $\begin{array}{l}\text { Close-ended, } \\
\text { Textbook-like }\end{array}$ & Demonstrate, Illustrate, Show, Solve & Crayons - see Figure 2 \\
\hline Interpretation & Identify, Generalize, Classify, Translate & How it's made - see Figure 1 \\
\hline Writing & Restate, Report, Summarize, Explain & Describe the 'event' in the video \\
\hline $\begin{array}{l}\text { Engineering Estimate } \\
\text { (Fact or Fiction) }\end{array}$ & Compare, Analyze, Model, Relate & Big Water Slide detailed in [20]. \\
\hline
\end{tabular}

Close-ended problems have a single correct answer, use the video to identify a problem to reverse engineer, and incorporate physical values from the video into the problem. The two examples cited possess the features of this problem type. The type and scope of close-ended problems have varied greatly, from mimicking textbook problems, problems with single questions, problems with multiple parts, and sets of conceptual questions.

Interpretation problems involve translating the events in an appropriately detailed video into a process flow diagram. For example, many "How it's made" videos available on the web describe 
an industrial process such as producing useful products at scale. In addition, interpretation using diagrams play a key role in solving most Engineering problems. Figure 2 is an Engineering diagram which shows the production of whiskey from the delivery of corn to the distillery to the final product. The attention to detail in identifying process units and streams from the video is the same problem-solving process used in the course. Also, the first part of the problem statement for 'How it is made - crayons' (figure 2) is another example of the interpretation type problem. It requires that the process flow diagram to be drawn and all streams labeled.

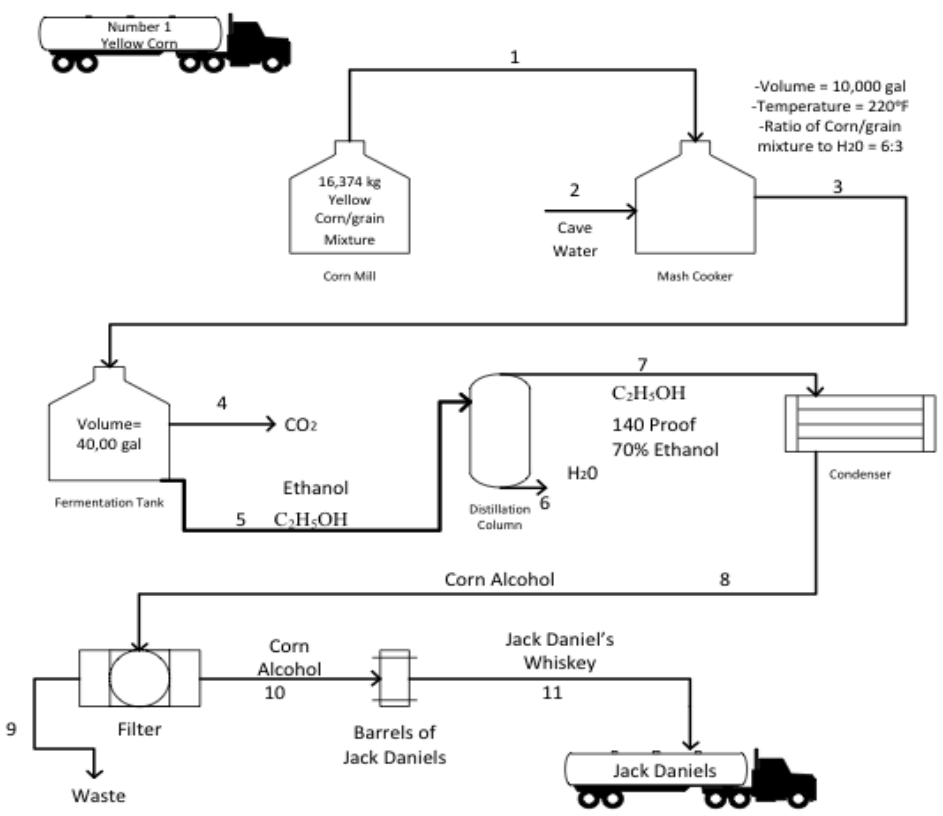

Figure 1. Example of student made process flow diagram from a material and energy balances course.

Figure 2 is an example of a problem involving a reacting system with recycles streams. Problems of this kind are one of the most difficult concepts for students learning material balances for the first time since they require additional evaluation in order to elucidate the flowrates at different streams. The problem statement includes a balanced chemical reaction, multiple parts/questions, and a standard, and somewhat generic, process flow diagram. The final part of the crayon problem involves finding the volumetric flow rate of the reactor effluent, fresh feed and product stream in standard units. Since the product is a solid (crayons), use of standard temperature and pressure to compare volumetric flow rate reveals a misconception. At this point, the instructor can decide how to proceed e.g., a timely class discussion on appropriate use of standard conditions and their effect (or lack of) on the density of gases, liquids and solid. 


Video title: How it's made - Crayons
Video link: http://www.youtube.com/watch?v=m5f7NuGkhXo
Problem Statement:
(60 Points)
As stated in the video a large scale factory can produce 30,000 crayons/hr. This problem focuses
on a much smaller scale factory, "Liberatore's Colors." The feed to the reactor is 150 mol/hr.
Within this stream, there is 60 mole percent steric acid $\left(\mathrm{C}_{18} \mathrm{H}_{36} \mathrm{O}_{2}\right), 33.75$ mole percent paraffin
wax ( $\left.\mathrm{C}_{20} \mathrm{H}_{52}\right)$, and the balance is Dr. Liberatore's own secret ingredient, the catalyst,
Liberatorium. The reaction proceeds as follows,
$110 \mathrm{C}_{18} \mathrm{H}_{36} \mathrm{O}_{2}+49 \mathrm{C}_{20} \mathrm{H}_{52} \rightarrow 74 \mathrm{C}_{40} \mathrm{H}_{82}+220 \mathrm{H}_{2} \mathrm{O}$
Dr. Liberatore's sixth or even seventh sense can just tell that the single pass conversion of steric
acid is $72 \%$. After the crayons are made, the excess reactants continue to a separator where water
is completely removed from the system with a small amount of Liberatorium. The composition
of this waste stream is 99.8 mole percent water, and the balance Liberatorium. The crayons leave
the separator as product. The fresh feed to the system is combined with a recycle stream that
leaves the separator and contains the excess steric acid, paraffin wax, and Liberatorium; which
then gets fed to the reactor. The fresh feed contains steric acid, paraffin wax, and Liberatorium.
- $(5$ points) Label the PFD with the component molar flow rates of each stream.
- $(37$ points) Find the flow rate of each component in the reactor effluent
- $(12$ points) Find the flow rate of the fresh feed
$(6$ points) Find the volumetric flow rate of the Product Stream in SCMM.

Figure 2. Student written reaction-recycle problem for material and energy balances course [20].

\section{Hypothesis}

Previous studies created a YouTube pedagogy and presented various successful pilot studies in a number of engineering courses. New research questions focus on examining the effects of studentgenerated YouTube problems on the development of problem solving skills of the students. The central hypothesis is that student-generated problems based on YouTube videos ("YouTube problems") promote better problem-solving skills than traditional textbook problems. Therefore, research questions seek to examine the quality of problem solving skills as well as the effects which creating and solving YouTube problems have on students' problem-solving skills, which will be elaborated on in the poster.

\section{$\underline{\text { Evaluation Techniques }}$}

In order to answer the research questions, student problem solving skills will be evaluated using several tools. First, 7-stage model consisting: Problem definition, representing the problem, organizing information, calculations, evaluating the solution, solution communication, and selfassessment (PROCESS) [35-39]. This tool has been used in engineering courses and on problems based on real-world scenarios similar to YouTube problems. It evaluates both the problem-solving process and the final solution. The rubrics for PROCESS was designed to track the problemsolving process for problems solved on a tablet. However, since the scope of this work is within gathering students' data from handwritten homework which is copied for later evaluation, PROCESS will be modified to match course content. 
In addition to the PROCESS tool, a second tool, Colorado Learning Attitudes about Science Survey (CLASS) is being implemented to measure of students' perception of problem solving ability. The CLASS has a reliability index of 0.90 . Although the instrument was designed for physics, this tool can be modified to match course content.

The rigor of student-created problems compared to textbook problems will be evaluated using the NASA Task Load Index (TLX). This tool measures workload using a six subscale: mental, physical, and temporal demands, frustration, effort, and performance [40-45]. This self-reported survey measures perceived mental effort and has a reliability index of 0.92 . Students will complete the NASA TLX for all the homework problems assigned. A comparison between groups will test whether YouTube problems are perceived by students to be equally as rigorous as textbook problems. To further examine the rigor of YouTube Problems composed by students, it will also be scored using a course-designed, analytic rubric. The rubric assesses four outcomes: integration of concepts, integration of video, clarity of problem statement, and accuracy of solution, will be modified to be more sensitive.

\section{Conclusion}

In summary, homework-style, YouTube-inspired problems are being implemented in an undergraduate course in Material and Energy balance. Example problems as well as preliminary responses and evaluation will help measure the effect of YouTube problems on problem-solving skills.

\section{Acknowledgments}

Caleb Sims help with cataloging YouTube problems is appreciated. This material is based upon work supported by the National Science Foundation under Grant No. DUE 1712186. Any opinions, findings, and conclusions or recommendations expressed in this material are those of the author(s) and do not necessarily reflect the views of the National Science Foundation. This work was completed within the framework of University of Toledo IRB protocol 202214.

\section{Bibliography}

1. Zax, D., Learning in 140-Characters Bities. ASEE PRISM, 2009: p. 1-3.

2. Bullard, L.G., The case against the use of solution manuals. Chemical Engineering Education, 2013. 47: p. 73.

3. Lang, J.M., Small Teaching: Everyday Lessons from the Science of Learning. 2016: John Wiley \& Sons.

4. Liberatore, M.W., Improved student achievement using personalized online homework for a couse in material and energy balances. Chemical Engineering Education, 2011. 45(3): p. 184-190.

5. Adams, W.K., et al. The design and validation of the Colorado Learning Attitudes about Science Survey. in Physics Education Research Conference 2004.

6. $\quad$ DAIGGER, G.T., et al., Real World Engineering Education Committee. 2012.

7. Vest, C.M., Infusing Real World Experiences into Engineering Education. 2012. 
8. Arnaud, C.H., Active Learning Beats Lectures. Chemical \& Engineering News, 2014. 92(22): p. 31-31.

9. $\quad$ Falconer, J.L., Why not try active learning? Aiche Journal, 2016. 62(12): p. 4174-4181.

10. Freeman, S., et al., Active learning increases student performance in science, engineering, and mathematics. Proceedings of the National Academy of Sciences, 2014. 111(23): p. 8410-8415.

11. Prather, E., A. Rudolph, and G. Brissenden, Using research to bring interactive learning strategies into general education mega-courses. Peer Review, 2011. 13(3): p. 27-30.

12. Prince, M., Does Active Learning Work? A Review of the Research. Journal of Engineering Education, 2004. 93(3): p. 223-231.

13. Chickering, A.W. and Z.F. Gamson, Seven Principles for Good Practice in Undergraduate Education. AAHE Bulletin, 1987: p. 1-7.

14. Falconer, J., Combining interactive thermodynamics simulations with screencasts and conceptests. Chemical Engineering Education, 2015. 50(1): p. 63-69.

15. Falconer, J.L., et al., Using screencasts in ChE courses. Chemical engineering education, 2009. 43(4): p. 302-305.

16. Falconer, J.L., et al., Chemical engineering screencasts. Chemical Engineering Education, 2012. 46(1): p. 58.

17. Walton, S.P., et al., Text messaging as a tool for engaging chemical engineering students. Chemical Engineering Education, 2012. 46(2): p. 80-86.

18. Liberatore, M.W., YouTube Fridays: Engaging the Net Generation in 5 Minutes a Week. Chemical Engineering Education, 2010. 44(3): p. 215-221.

19. Liberatore, M.W., Active Learning and Just-in-time Teaching In a Material and Energy Balances Course. Chemical Engineering Education, 2013. 47(3): p. 154-160.

20. Liberatore, M.W., et al., Student-created homework problems based on YouTube videos. Chemical Engineering Education, 2013. 47(2): p. 122-132.

21. Liberatore, M.W., C.R. Vestal, and A.M. Herring, YouTube Fridays: Student led development of engineering estimate problems. Advances in Engineering Education, 2012. 3(1): p. 1-16.

22. Liberatore, M.W., C.R. Vestal, and R.M. Morrish, Effectiveness of Just In Time Teaching on Student Achievement in an Introductory Thermodynamics Course. Advances in Engineering Education, 2017. in press.

23. Edgar, T.F., Information Technology and ChE Education: Evolution or Revolution? Chemical Engineering Education, 2000(Fall): p. 290-295.

24. Hadley, K.R. and K.A. Debelak, Wiki technology as a design tool for a capstone design course. Chemical Engineering Education, 2009. 43(3): p. 194-200.

25. Doyle, T. and T. Zakrajsek, Learner Centered Teaching: Putting the Research on Learning into Practice. 2011: Stylus Publishing.

26. Pretz, J.E., A.J. Naples, and R.J. Sternberg, Recognizing, Defining, and Representing Problems, in The Psychology of Problem Solving, J.E. Davidson and R.J. Sternberg, Editors. 2003, Cambridge University Press: Cambridge, UK.

27. Medina, J., Brain Rules 12 Principles for Surviving and Thriving at Work, Home, and School. 2008: Pear Press.

28. Al-Balushi, S.M. and S.H. Al-Hajri, Associating animations with concrete models to enhance students' comprehension of different visual representations in organic chemistry. Chem. Educ. Res. Pract., 2014. 15(1): p. 47-58. 
29. Brown, J.R. and M.B. McGrath, Visual learning for science and engineering. IEEE Comput Graph Appl, 2005. 25(5): p. 56-63.

30. Stelzer, T., et al., Comparing the efficacy of multimedia modules with traditional textbooks for learning introductory physics content. American Journal of Physics, 2009. 77(2): p. 184.

31. Velazquez-Marcano, A., et al., The Use of Video Demonstrations and Particulate Animation in General Chemistry. Journal of Science Education and Technology, 2004. 13(3): p. 315-324.

32. Bransford, J.D., A.L. Brown, and R.R. Cocking, eds. How People Learn: Brain, Mind, Experience, and School: Expanded Edition. 2000, National Academies Press.

33. Tasker, R. and R. Dalton, Research into practice: visualisation of the molecular world using animations. Chemistry Education Research and Practice, 2006. 7(2): p. 141-159.

34. Bloom, B.S., ed. Taxonomy of Education Objectives: the classification of educational goals. 1956, Longsmans, Green: New York.

35. Benson, L., et al. CU thinking problem solving strategies revealed. in ASEE Annual Meeting. 2011. Vancouver, BC.

36. Grigg, S.J. and L. Benson. Effects of Student Strategies on Successful Problem Solving. in ASEE Annual Meeting. 2012. San Antonio, TX.

37. Grigg, S.J. and L. Benson. Promoting problem solving proficiency in first year engineering process assessment. in ASEE Annual Meeting. 2015. Seattle, WA.

38. Grigg, S.J. and L.C. Benson, A coding scheme for analysing problem-solving processes of first-year engineering students. European Journal of Engineering Education, 2014. 39(6): p. 617-635.

39. Grigg, S.J., et al. Process analysis as a feedback tool for development of engineering problem solving skills. in ASEE Annual Meeting. 2013. Atlanta.

40. Html based TLX. Simple and easily protable. [cited 2016 September]; Available from: https:/www.keithv.com/software/nasatlx/.

41. Grier, R.A., How High is High? A Meta-Analysis of NASA-TLX Global Workload Scores. Proceedings of the Human Factors and Ergonomics Society Annual Meeting, 2015. 59(1): p. 1727-1731.

42. Grigg, S.J., S.K. Garrett, and L. Benson. Using the NASA-TLX to Assess First Year Engineering Problem Difficulty. in IIE Annual Conference. 2012.

43. Hart, S.G. NASA-Task Load Index (NASA-TLX); 20 Years Later. in Human Factors and Ergonomics Society Annual Meeting. 2006.

44. Hart, S.G. and L.E. Staveland, Development of NASA-TLX (Task Load Index): Results of Empirical and Theoretical Research, in Human Mental Workload. 1988. p. 139-183.

45. Sharek, D., A Useable, Online NASA-TLX Tool. Proceedings of the Human Factors and Ergonomics Society Annual Meeting, 2011. 55(1): p. 1375-1379. 